\title{
Correction to: Mesoporous silica-based nanoplatforms for the delivery of photodynamic therapy agents
}

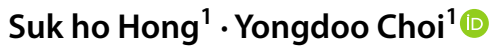

Published online: 30 October 2018

(c) The Author(s) 2018

\section{Correction to: \\ Journal of Pharmaceutical Investigation (2018) 48:3-17 https://doi.org/10.1007/s40005-017-0356-2}

The article "Mesoporous silica-based nanoplatforms for the delivery of photodynamic therapy agents", written by Suk ho Hong and Yongdoo Choi, was originally published electronically on the publisher's internet portal (currently SpringerLink) on 9 September 2017 without open access.

With the authors' decision to opt for Open Choice the copyright of the article changed on 30 October 2018 to () The Author(s) 2017 and the article is forthwith distributed under the terms of the Creative Commons Attribution 4.0 International License (http://creativecommons.org/licen ses/by/4.0/), which permits use, duplication, adaptation, distribution and reproduction in any medium or format, as long as you give appropriate credit to the original author(s) and the source, provide a link to the Creative Commons license and indicate if changes were made.

The original article can be found online at https://doi.org/10.1007/ s40005-017-0356-2.

Yongdoo Choi

ydchoi@ncc.re.kr

1 Biomarker Branch, National Cancer Center, 323 Ilsan-ro,

Goyang-si, Gyeonggi-do 10408, Republic of Korea 